Ann. Biol. anim. Bioch. Biophys., I969, 9 (3), 329-349.

\title{
RECHERCHES EXPERIMENTALES SUR LA MATURATION IN VITRO DES OVOCYTES DE TRUIE ET DE VEAU
}

\author{
W.-D. FOOTE ( $\left.{ }^{(}\right)$et C. THIBAULT \\ avec la collaboration de Micheline Gérard et Anne-Marie Mélières \\ Station centrale de Physiologie animale, \\ Centre national de Recherches zootechniques 78 - Jouy-en-Josas \\ Institut national de la Recherche agronomique
}

\section{SOMMAIRE}

Nous avons étudié la possibilité d'une maturation expérimentale in vitro dans différents milieux de culture classiques d'ovocytes de Veaux ou de Truie prélevés dans des follicules de taille petite ou moyenne. La reprise de la méiose se produit dans la presque totalité des ovocytes. Cependant, l'étude cytologique révéla des anomalies au niveau des fuseaux de maturation. Nous apportons la preuve que la rupture du contact entre l'ovocyte et les cellules de la couche interne du follicule ou Granulosa entraîne la reprise de la méiose et que, par conséquent, c'est la présence de cette assise cellulaire qui, dans le follicule, maintient l'ovocyte à l'état dictyé.

Diverses expériences pour obtenir la maturation intrafolliculaire in vitro de follicules de Veau ou de Truie ont échoué.

\section{INTRODUCTION}

L'ovocyte des Mammifères demeure dans l'ovaire pendant des mois ou des années après sa formation et ne reprend naturellement l'achèvement de sa méiose que sous l'influence des hormones hypophysaires déchargées soit spontanément au début de l'œstrus, soit sous l'influence de l'accouplement. Cette décharge hormonale agit sur l'ovocyte par l'intermédiaire des cellules folliculeuses de la thèque, de la granulosa et des cellules périovocytaires (corona radiata).

Cependant, la reprise de la méiose depuis la disparition du noyau dictyé jusqu'à

(1) Adresse actuelle : Animal Science Divisicn. University of Nevada. Reno, Nevada, 89, 507., U. S. A. 
la formation du deuxième fuseau de maturation, se produit également dans deux circonstances :

- dans les follicules en atrésie de la Ratte hypophysectomisée (BENort et MAULÉon, communication personnelle) ;

- après extraction de follicules à antrum et culture in vitro en l'absence d'hormones gonadotropes : Lapine (Pincus et Enzman, I935; Chang, I955); Souris, Brebis, Vache, Truie, Singe (Edwards, I $965 a$ ) ; Singe (Suzuki et MastroiannI, I966) ; Femme (Edwards, I965 $b$; Edwards, Bavister et Steptoe, I969).

In vitro la formation du premier fuseau de maturation, puis du premier globule polaire, paraît s'accomplir dans des délais comparables, ou légèrement supérieurs, à ceux observés au cours du cycle sexuel entre la décharge gonadotrope et l'ovulation. C'est ainsi qu'avec l'œuf humain, la transformation du noyau dictyé se produit 25 heures après la mise en culture, et l'émission du premier globule polaire, entre 36 et 43 heures (EDwards, I 655 ) et avec l'œuf de Lapine, I6 heures après mise en culture, la présence de métaphases II est fréquente (KARDYMowIcz, communication personnelle).

La maturation in vitro est-elle réelle ou n'est-ce qu'une forme de dégénérescence?

Les observations cytologiques de Chang (I955), Edwards (I965 $a$ et $b$ ), SuzuKI et Mastroianni (Ig66), par suite des techniques de coloration et de fixation utilisées (acide acétique, colorant lacmoïde, examen in toto) sont trop sommaires pour permettre d'affirmer que la maturation se produit normalement.

Si la maturation in vitro est réelle, comment expliquer que la maturation in vivo ne se produise que dans les ovocytes des plus gros follicules sous l'influence d'une stimulation gonadotrope, alors qu'in vitro, elle se produirait dans des ovocytes provenant de follicules dans des états fort différents de maturité et en l'absence de gonadotropines, comme chez l'animal hypophysectomisé.

C'est pour répondre à ces questions que nous avons entrepris les recherches qui font l'objet de ce mémoire.

\section{MATÉRIEL ET MÉ'THODES}

Nous avons utilisé des veaux de 3 à 4 mois ou des vaches adultes de différentes races et des truies pubères nullipares de race Large White. Les animaux étaient abattus à n'importe quel moment du cycle, à proximité du laboratoire et les ovocytes ou follicules mis en culture dans les Io à $30 \mathrm{mi}$ nutes suivant la mort de l'animal.

Les ovocytes ont été prélevés par aspiration dans des follicules à antrum de taille moyenne et non dans des follicules en phase de grand accroissement après stimulation par des hormones gonadotropes exogènes comme l'ont fait BIGgers, WhitTingham et Donahue (I967) ; DonahuE et STERN (1968) pour l'étude in vitro des métabolites énergétiques nécessaires à l'ovocyte de Souris en phase de maturation finale.

Tous les ovocytes ainsi recueillis étaient entourés de leur corona radiata. Par commodité, nous utiliserons le terme ovocyte pour l'ensemble ovocyte-corona radiata.

Les follicules étaient détachés avec des ciseaux fins à rotation et ensuite pelés finement à la pince sous la loupe binoculaire. Cette technique préserve totalement la granulsosa et sa membrane basale, ainsi que quelques assises de la thèque interne. Le traumatisme périphérique est minime et le pourtour du follicule, après 30 à 48 heures de culture, est très rarement pycnotique.

Nous avons employé comme milieux de culture du liquide de Brinster, ou le I99 ( ${ }^{(1)}$ avec tampon

(1) 199 : Pasteur ou Microbiological. 
bicarbonate, additionné de sérum homologue ou de sérum de poulain ( 15 p. 100) et d'extrait embryonnaire de poulet (20 p. 100), préparé au laboratoire. Les différents milieux furent utilisés avec ou sans insuline $(5 \mu \mathrm{g} / \mathrm{ml})$, avec ou sans hormones gonadotropes (FSH et LH, CNRS-ovine), avec ou sans stéroïdes ; généralement, $100 \mu \mathrm{g} / \mathrm{ml}$ de streptomycine furent ajoutés aux milieux. Il nous a paru que la meilleure préservation de l'ensemble ovocyte et cellules de la corona était observé avec du $199+$ I5 $\mathrm{p}$. 100 de sérum de poulain $+20 \mathrm{p}$. 100 d'extrait embryonnaire de poulet, de l'insuline et de la streptomycine (milieu A), sans cependant que l'avantage sur le sérum homologue soit certain. Les follicules étaient cultivés sur grilles ou filtres millipores en culture organotypique et les ovocytes, en tubes ou plus souvent en salières.

Les cultures ont été réalisées sous air $+5^{\circ} \mathrm{CO}_{2}$ à la pression atmosphérique ou sous des pressions de 300 et 700 millibars. L'augmentation de pression améliore la survie des cellules de la granulosa (fréquence élevée de cellules en mitoses, absence de picnose), mais ne nous a pas permis d'obtenir une bonne préservation des ovocytes, aussi n'en ferons-nous pas état.

La durée normale de maturation est d'une trentaine d'heures chez la Vache et d'environ 36 heures chez la Truie, aussi avons-nous généralement choisi des durées de culture comprises entre 30 et 48 heures pour éviter que les modifications que l'on sait intervenir au cours du vieillissement de l'ovocyte après l'ovulation, ne conduisent à une interprétation erronée des phénomènes nucléaires survenus dans les ovocytes cultivés in vitro.

Après culture, les pièces ont été fixées au Bouin Hollande incluses, coupées à Io $\mu$ et colorées selon les techniques habituelles (ThIBAULT, 1949).

\section{RÉSULTATS}

\section{Culture in vitro d'ovocytes de Truie ou de Veau}

a) Truie.

Le tableau I montre, pour 23 ovocytes de Truie cultivés 30 ou 48 heures, une reprise quasi générale de la méiose : 20 sur 23 ovocytes, soit $87 \mathrm{p}$. Ioo, étaient en métaphase I ou en métaphase II.

b) Veau.

Le tableau 2 résume trois des principaux essais avec du sérum de veau, additionné ou non d'insuline et avec ou sans hormones gonadotropes (FSH et LH-CNRS-ovine).

Il ressort clairement que 98 p. Ioo des ovocytes extraits de follicules à des stades divers du développement folliculaire tendent à achever leur méiose. Après 30 heures environ de culture, $40 \mathrm{p}$. Ioo atteignent la deuxième métaphase de maturation après avoir émis le premier globule polaire, les autres évoluent plus lentement et on peut même penser que la plupart n'auraient pas évolué au-delà du stade qu'ils ont atteint après 30 heures.

Les fuseaux de maturation présentent souvent des anomalies : c'est ainsi que I52/I62 fuseaux de première division et $\mathrm{I}_{44} / \mathrm{I} 55$ fuseaux de deuxième division d'ovocytes de veaux présentaient des tétrades ou des diades sur une plaque métaphasique ou un fuseau anormaux. Généralement, le fuseau se présente en tonnelet avec les fibres relâchées et non centrées sur deux pôles, comme elles le sont normalement (p1. $\mathrm{x}$, fig. I-4).

KARDYMOWICZ (communication personnelle) a observé dans l'ovocyte de Lapine la formation amitotique d'un globule polaire : à partir du noyau dictyé central se détache une masse de chromatine qui est expulsée et forme un globule polaire. Il ne nous est pas possible d'affirmer qu'un tel phénomène peut se produire chez la Vache, bien que nous ayons retrouvé des globules polaires semblables et dans l'ovocyte un 


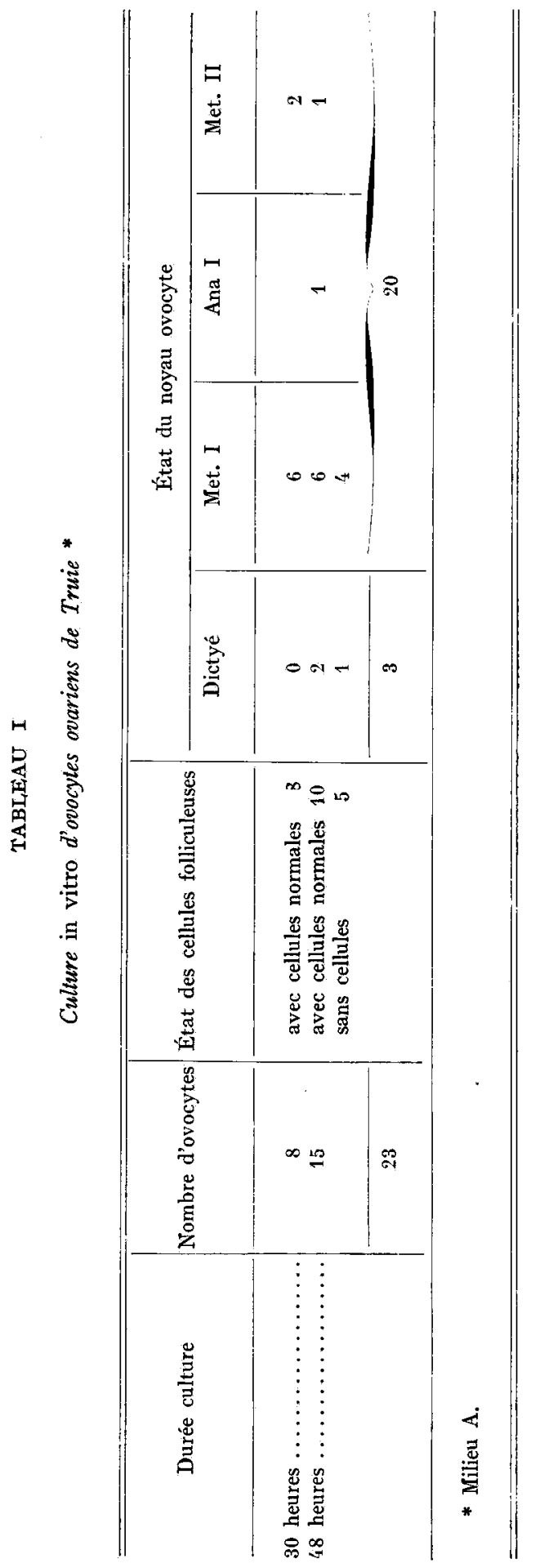




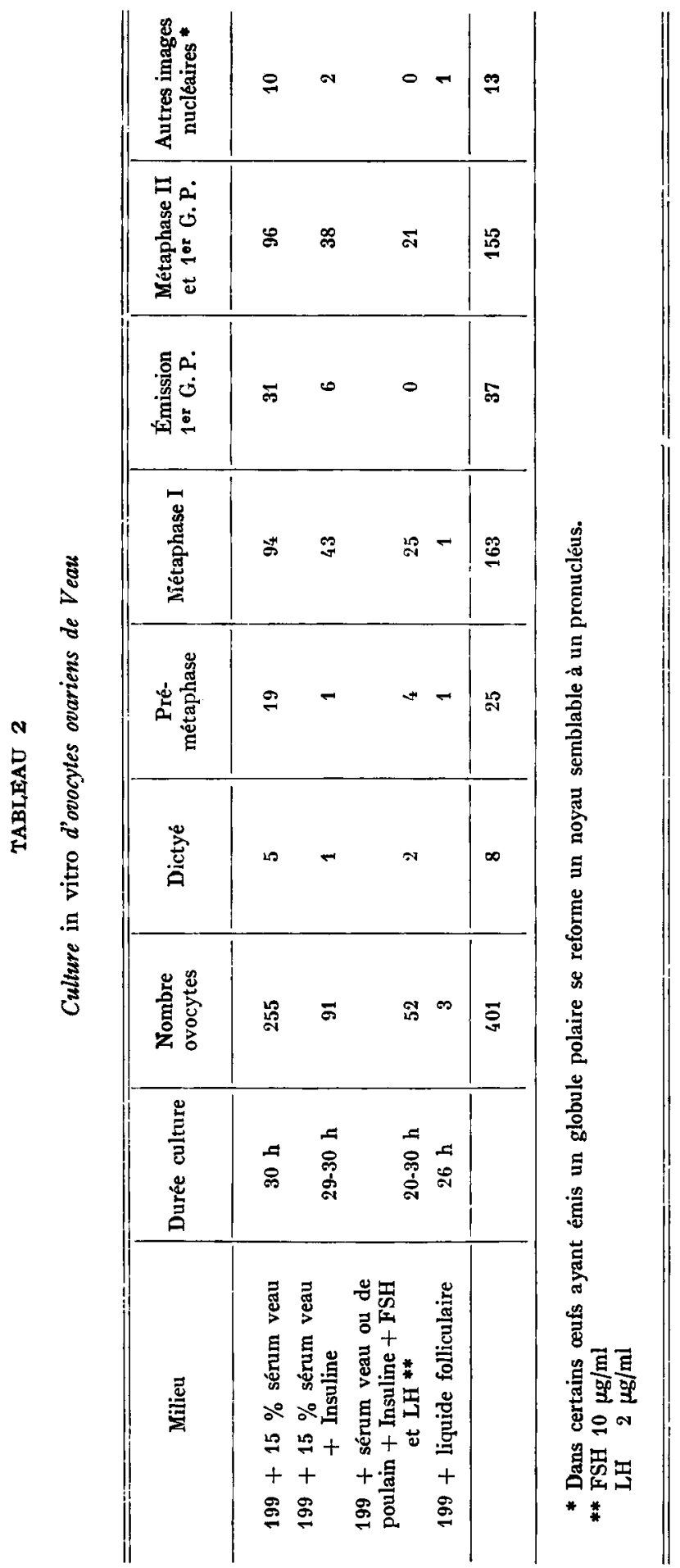


noyau tout à fait identique à un pronucléus et absolument plus à un noyau dictyé. Nous avons également observé un ovocyte de vache contenant deux noyaux sans aucune émission de globule polaire. Nous avons qualifié cette situation caractérisée par la présence de noyaux semblables à des pronuclei, de pseudo-parthénogenèse (pl. I, fig. 5-6).

\section{Culture in vitro de follicules de Truie ou de Veau}

Pour qu'une survie de la totalité de l'explant soit assurée en culture organotypique, sa taille ne peut guère excéder un à deux millimètres de diamètre; ceci nous a conduit à ne cultiver que des follicules à antrum de petite taille.

En présence d'extrait embryonnaire de poulet, les cellules du follicule et celles de la granulosa en particulier, montrent de nombreuses mitoses. Même lorsque dans certaines parties de la granulosa, les cellules sont pycnotiques, ce qui est très fréquent. dans les plus gros follicules, dans les zones saines on observe toujours des mitoses.

\section{a) Truie.}

Le tableau 3 (première ligne), montre un maintien parfait de l'état dictyé dans es ovocytes intrafolliculaires (pl. 2, fig. 8).

TABLEAU 3

Culture in vitro de follicules de Truie

\begin{tabular}{|c|c|c|c|c|}
\hline \multirow[b]{2}{*}{ Milieu de culture } & \multirow{2}{*}{$\begin{array}{l}\text { Nombre } \\
\text { de follicules }\end{array}$} & \multicolumn{3}{|c|}{ État des } \\
\hline & & $\begin{array}{c}\text { Cellules } \\
\text { folliculeuses }\end{array}$ & Hypophyse & Noyau/ovocyte \\
\hline $\mathbf{A}$ & 9 & $\begin{array}{l}\text { 5. Normales, } N \\
\text { 4. Pycnotiques, } P\end{array}$ & & 9 Dictyé \\
\hline A + Hypophyse & 2 & 2. $\mathrm{N}$ & Normaux & 2 Dictyé \\
\hline$A+$ Progestérone & 6 & 4. $N+2 . P$ & & 6 Dictyé \\
\hline $\begin{array}{c}\text { A }+ \text { Progestérone } \\
+ \text { Hypophyse }\end{array}$ & 3 & 2. $\mathrm{N}+1 . \mathrm{P}$ & Normaux & 3 Dictyé \\
\hline
\end{tabular}

(Durée de culture, 2-3 jours, rarement 4).

b) Veau.

Le tableau 4 confirme dans son ensemble cette première conclusion, même après. 3-6 jours de culture le stade dictyé persiste et sur II9 follicules cultivés, Ior fois lesovocytes ont été retrouvés au stade dictyé. On remarque cependant, que quelques ovocytes sont en prométaphase (vacuolisation du nucléole, apparition des chromosomes ou diacinèse). Il est possible d'associer cette reprise de la méiose à une dégéné-- 
rescence pycnotique de la granulosa ou de cellules périovocytaires. Une indication de l'existence d'une telle relation nous a été fournie par l'examen d'un follicule cultivé 48 heures et contenant deux ovocytes : l'un, demeuré au stade dictyé, était entouré de cellules périovocytaires et relié à une granulosa histologiquement normales; au voisinage du second, au contraire, la granulosa et les cellules périovocytaires étaient pycnotiques et le noyau était en prométaphase (pl. 3, fig. II, I3 et I4).

\section{TABLEAU 4}

Culture de follicules de Veau

\begin{tabular}{|c|c|c|c|c|c|c|c|}
\hline \multirow{2}{*}{ Milieu de culture } & \multirow{2}{*}{$\begin{array}{l}\text { Durée de } \\
\text { culture } \\
\text { (heures) }\end{array}$} & \multirow{2}{*}{$\begin{array}{l}\text { Nombre } \\
\text { folli- } \\
\text { cules }\end{array}$} & \multirow{2}{*}{$\begin{array}{l}\text { État } \\
\text { cellules } \\
\text { granu- } \\
\text { losa: } \\
\text { pycnose }\end{array}$} & \multicolumn{4}{|c|}{ État de l'ovocyte } \\
\hline & & & & Dictyé & $\begin{array}{c}\text { PM pré- } \\
\text { métaphase }\end{array}$ & $\begin{array}{c}1{ }^{\text {er }} \\
\text { fuseau }\end{array}$ & $\begin{array}{c}2^{\bullet} \\
\text { fuseau }\end{array}$ \\
\hline $199+$ sérum de poulain & $\begin{array}{l}48 \\
24\end{array}$ & $\begin{array}{l}22 \\
23\end{array}$ & $\begin{array}{l}22 / 22 \\
13 / 23\end{array}$ & $\begin{array}{l}12 \\
19\end{array}$ & $\begin{array}{l}7 \\
4\end{array}$ & $\begin{array}{l}3 \\
0\end{array}$ & $\begin{array}{l}0 \\
0\end{array}$ \\
\hline $199+$ E. E. P. + insuline & 24 & 15 & $9 / 15$ & 15 & 0 & 0 & $\mathbf{0}$ \\
\hline $\begin{aligned} 199 & + \text { E. E. P. } \\
& + \text { sérum veau } \\
& + \text { insuline }\end{aligned}$ & 24 & 18 & $13 / 17$ & 15 & 2 & 0 & 0 \\
\hline $\begin{array}{l}199+\text { E. E. P. } \\
+ \text { sérum poulain } \\
+ \text { insuline }\end{array}$ & $24-48$ & 27 & $8 / 27$ & 26 & 1 & 0 & 0 \\
\hline $\mathbf{A}$ & $72-144$ & 15 & $5 / 15$ & 14 & 1 & 0 & $\mathbf{0}$ \\
\hline 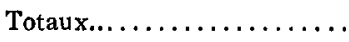 & & 119 & & 101 & 14 & 3 & 0 \\
\hline
\end{tabular}

Cette relation entre l'intégrité des cellules de la granulosa, des cellules périovocytaires et le maintien de l'ovocyte à l'état dictyé n'est pas aussi nette chez la Truie : dans des follicules de petite taille et après culture, l'ovocyte entouré d'une couronne assez fragile de cellules périovocytaires, peut se trouver complètement détaché de la granulosa sans que toujours le stade dictyé soit dépassé (pl. 2, fig. 5).

Malgré des différences de détails entre l'ovocyte de Truie et celui de Vache, ces expériences montrent :

Io que le "blocage » de la méiose à l'état diplotène-dictyé résulte d'une inhibition que subit l'ovocyte à l'intérieur du follicule;

$2^{0}$ que, lorsque cette inhibition est levée, soit expérimentalement par transport de l'ovocyte hors du follicule, soit par rupture de la liaison Granulosa-ovocyte, les mitoses réductionnelles se forment, mais sont fréquemment anormales.

Nous avons tenté de préciser quelle était l'origine de l'inhibition, exercée à l'intérieur du follicule, par des " greffes » in vitro d'ovocytes étrangers, à l'extérieur ou à l'intérieur de follicules en culture. 


\section{Greffe d'ovocytes sur différentes assises folliculaires}

A) Culture d'ovocytes au contact du follicule.

Au contact d'un follicule, préparé comme il a été indiqué, sont placés des ovocytes prélevés dans des follicules du même ovaire et l'ensemble est cultivé 48 heures. Les ovocytes propres des follicules servent de témoin.

Il y a greffe quand les cellules périovocytaires se lient aux cellules de la thèque ou de la granulosa sans solution de continuité.

a) Truie.

L'expérience I du tableau 5 montre que 5 ovocytes dont les cellules périovocytaires s'étaient greffées à la périphérie de trois follicules, sont en métaphase I ou en métaphase II. Les ovocytes témoins intrafolliculaires sont demeurés au stade dictyé. (pl. 2. fig. 9).

TABLEAU 5

Culture d'ovocytes sur follicule (Truie)

\begin{tabular}{|c|c|c|c|c|c|c|}
\hline \multirow{2}{*}{ Type de culture } & \multirow{2}{*}{$\begin{array}{c}\text { Nombre } \\
\text { de follicules }\end{array}$} & \multirow{2}{*}{$\begin{array}{l}\text { État des cellules } \\
\text { folliculeuses } \\
\text { du follicule }\end{array}$} & \multicolumn{3}{|c|}{ État ovocyte greffé } & \multirow{2}{*}{$\begin{array}{l}\text { Etat de } \\
\text { l'ovocyte } \\
\text { du follicule }\end{array}$} \\
\hline & & & Dictyé & M I & M II & \\
\hline 1 & 3 & 3. $\mathrm{N}$ & $0 / 5$ & $1 / 5$ & $4 / 5$ & 3 Dict. \\
\hline 2 & 6 & 5. $\mathbf{N}+1 . P$ & $7 / 8$ & & $1 / 8$ & \\
\hline 3 & 4 & $\begin{array}{l}\text { 2. } \mathrm{N} \\
\text { 2. } \mathrm{P}\end{array}$ & $\begin{array}{l}7 / 8 \\
2 / 3\end{array}$ & $1 / 8$ & $1 / 3$ & \\
\hline & & & & & & \\
\hline
\end{tabular}

1

2
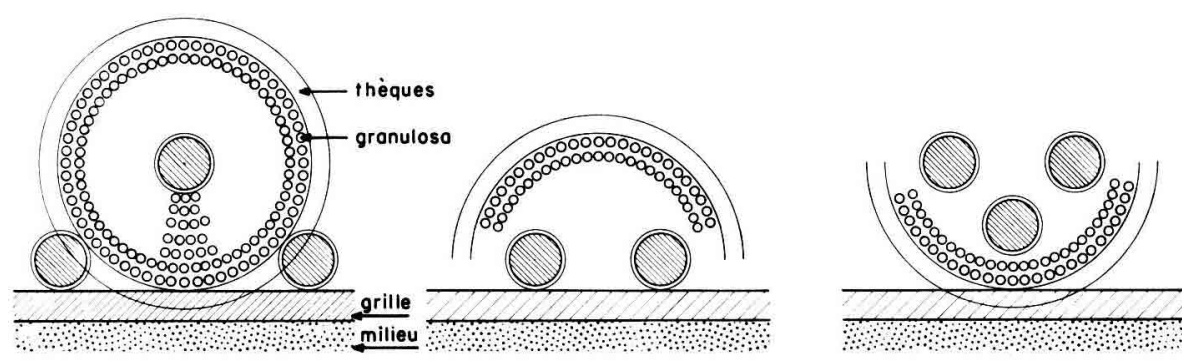

b) Veau.

La même expérience répétée avec des follicules et des ovocytes de veau aboutit au même résultat. 
B) Culture d'ovocytes au contact de la granulosa.

Les follicules sont coupés par moitié et des ovocytes provenant d'autres follicules sont soit recouverts par le demi-follicule, soit placés dans la coupe formée par le demi-follicule tourné vers le haut.

a) Truie.

Ces expériences présentées dans le tableau 5 (expériences 2 et 3 ) montrent que le rétablissement d'un contact entre l'ovocyte et la granulosa suffit à assurer le maintien de 1'état dictyé (pl. 2, fig. Io).

b) Veau.

Les résultats sont à la fois plus nuancés et plus intéressants ; en effet, le maintien de l'état dictyé dépend de la bonne jonction entre les cellules de la granulosa et les cellules périovocytaires, ainsi que de l'état fonctionnel de ces cellules : lorsque de nombreuses cellules sont pycnotiques, le noyau dictyé évolue vers la métaphase I. Les figures 15 à 18 illustrent clairement cette nécessité d'une jonction fonctionnelle.

4. Action des hormones sur la maturation de l'ovocyte intrafolliculaire in vitro

\section{A) Culture associée hypophyse-follicule.}

Au contact de follicules de Veau et de Truie, il est très facile de cultiver des fragments d'hypophyse du même animal, dans le milieu $A$, les pycnoses sont rares et les mitoses dans le tissu hypophysaire sont nombreuses. L'association entre les cellules hypophysaires et les cellules de la thèque est étroite.

Malgré cette situation favorable, aucune réactivation du noyau de l'ovocyte n'a été observée (tabl. 6 et pl. 3 fig. 12).

TABLEAU 6

Follicules de Veau cultivés in vitro en présence de fragments d'hypophyse *

\begin{tabular}{|c|c|c|c|c|c|}
\hline \multirow{2}{*}{$\begin{array}{c}\text { Durée de la culture } \\
\text { (heures) }\end{array}$} & \multirow{2}{*}{$\begin{array}{c}\text { Nombre } \\
\text { de follicules }\end{array}$} & \multirow{2}{*}{$\begin{array}{c}\text { Cellules } \\
\text { granulosa } \\
\text { pycnotiques }\end{array}$} & \multicolumn{3}{|c|}{ État de l'ovocyte } \\
\hline & & & Dictyé & PMI & M I \\
\hline 24 & 4 & $1 / 4$ & 4 & 0 & 0 \\
\hline 48 & 6 & $2 / 6$ & 6 & 0 & c \\
\hline 72 & 4 & $1 / 4$ & 4 & 0 & 0 \\
\hline 96 & 2 & 0 & 2 & 0 & $c$ \\
\hline
\end{tabular}

* Milieu de culture : A. 
B) Culture de follicules en présence de FSH ou de LH.

FSH et $\mathrm{L} H$, d'origine ovine, ont été ajoutées au milieu $\mathrm{A}$ dans la proportion de $20 \mu \mathrm{g} / \mathrm{ml}$ de FSH et de $2 \mu \mathrm{g} / \mathrm{ml}$ de LH. Elles furent, dans la majorité des expériences, ajoutées ensemble (tabl. 7).

\section{TABLEAU 7}

Follicules de veau cultivés in vitro en présence de 0,1 à $1 / \mu \mathrm{g}$ de $\mathrm{FSH} / \mathrm{ml}$ et/ou de 0,1 à $1 / \mu \mathrm{g}$ de $\mathrm{LH} / \mathrm{ml}$ dans le milieu

\begin{tabular}{|c|c|c|c|c|c|}
\hline & \multirow{2}{*}{$\begin{array}{c}\text { Nombre } \\
\text { de follicules }\end{array}$} & \multirow{2}{*}{$\begin{array}{c}\text { Cellules } \\
\text { granulosa } \\
\text { pycnotiques }\end{array}$} & \multicolumn{3}{|c|}{ Etat de l'ovocyte } \\
\hline & & & Dictyé & PM & $\mathrm{MI}$ \\
\hline $43-44$ heures & 49 & $41 / 49$ & 27 & 16 & 6 \\
\hline
\end{tabular}

Une proportion relativement élevée d'ovocytes (22/49) ont repris leur méiose. Il nous semble que ce résultat doit être imputé à la proportion élevée de follicules présentant une granulosa pycnotique plus qu'à une action directe de FSH ou de LH. Mais il est possible que cette proportion élevée de follicules pycnotiques soit due à l'action de FSH et de LH.

C) Culture en présence de stéroïdes.

Le sulfate d'œstrone ou la progestérone, soit seules (tabl. 3 et 8), soit associées à des cultures de follicules en présence d'hypophyse (tabl. 3), ne permettent pas la levée de l'inhibition de la méiose.

\section{TABLEAU 8}

Action des stéroïdes sur le follicule et l'ovocyte cultivés in vitro

\begin{tabular}{|c|c|c|c|}
\hline $\begin{array}{c}\text { Durée } \\
\text { de culture }\end{array}$ & $\begin{array}{l}\text { Nombre } \\
\text { follicules }\end{array}$ & $\begin{array}{c}\text { Cellules } \\
\text { granulosa } \\
\text { pycnotiques }\end{array}$ & Noyaux dictyés \\
\hline \multicolumn{4}{|c|}{ - Progestérone* } \\
\hline $48 \mathrm{~h}$ & 10 & 4 & 10 \\
\hline \multicolumn{4}{|c|}{ - Estrone injectée dans le follicule ** : } \\
\hline $\begin{array}{c}\text { Veau : } 26 \mathrm{~h} \\
\text { Truie : } 30-72 \mathrm{~h}\end{array}$ & $\begin{array}{l}2 \\
3\end{array}$ & $\begin{array}{l}1 \\
0\end{array}$ & $\begin{array}{l}2 \\
3\end{array}$ \\
\hline $\begin{array}{l}\text { * Solubilité } \\
\text { ** } 2 \mu \mathrm{g} / \mathrm{ml} \text {. }\end{array}$ & imum ; & & \\
\hline
\end{tabular}




\section{DISCUSSION}

I0 Nos observations confirment les travaux antérieurs de PINCUs et ENZManN (I935 $a$ et $b$ ) ; Chang (I955) ; Edwards (I965 $a$ et $b$ ) ; Suzuki et Mastroianni (1966), sur la reprise de la méiose de l'ovocyte provenant de follicules à Antrum et cultivés dans différents milieux.

Elles apportent une précision qualitative sur les figures mitotiques observées, grâce aux techniques cytologiques employées : la position si caractéristique du $2^{e}$ fuseau de maturation dans l'ovocyte fraîchement ovulé, parallèle au bord de l'ovocyte, n'a été que très rarement observée; le plus souvent, le fuseau occupe une position plus ou moins oblique, situation analogue à celle que l'on observe dans l'ovocyte vieillissant après 1'ovulation. Il en est de même de l'éparpillement des fibres fusoriales aux deux pôles des fuseaux, image fréquemment rencontrée dans les ovocytes cultivés des deux espèces.

Enfin, la présence d'un globule polaire avec une masse de chromatine ponctuelle et d'un noyau (ou de deux) ressemblant à des pronuclei ( 13 fois sur 402 ovocytes de veau) est à rapprocher des observations de CHANG (I955), BARRos et AusTin (I968). ChANG signale l'existence d'œufs "parthénogénétiques " parmi les ovocytes ovariens immatures qu'il avait replacés dans les trompes de la Lapine. BARRos et AusTiN observent des " pronuclei " dans des ovocytes ovariens de Hamster ayant reçu de l'actinomycine le jour précédant le jour probable de l'ovulation, l'antibiotique ayant empêché l'ovulation.

Dans cette étude, nous n'avons pas cherché à eprouver la fécondabilité des œufs maturés in vitro, mais les résultats de CHANG (I955), après transfert dans les trompes d'une Lapine, ont montré qu'une proportion non négligeable était fécondable (I9 p. Ioo) mais que fort peu de ces œufs se développaient normalement (4 p. Ioo). EDwARDS, BAvister et STEPTOE (I969) ont obtenu quelques fécondations in vitro d'ovocytes ovariens humains maturés in vitro. Que de tels ovocytes soient fécondables n'a rien d' étonnant, puisque nous avons observé quẹ des ovocytes ovariens de Lapines accouplées pouvaient être fécondés in vitro juste après l'émission de leur premier globule polaire (DuQUESNE et ThIBAuLT, non publié). Que leur développement soit anormal peut découler des anomalies dans les divisions de maturation, c'est également 1'opinion d'EDWARDs et al. (I969).

$2^{\circ}$ Cultivé dans le même milieu, mais emprisonné dans son follicule ou "greffé " sur la granulosa, l'ovocyte demeure à l'état dictyé. Certaines " greffes " montrent des stades divers de contact et l'étude des cas individuels conduit à la conclusion que seules les cellules de la granulosa sont capables de maintenir l'inhibition de la méiose. Au contact des cellules de la thèque, la métaphase de première division apparaît dans l'ovocyte.

On est donc conduit à l'idée que le maintien de l'ovocyte au stade dictyé résulte d'une inhibition permanente exercée par les cellules de la granulosa. Cette inhibition ne paraît pouvoir s'exercer chez la Vache que par un contact cellulaire direct entre granulosa et corona radiata, alors que chez la Truie, le liquide folliculaire peut servir d'intermédiaire. 
Quand ce contact est rompu par ponction de l'ovocyte hors du follicule (culture in vitro), ou que les cellules responsables de l'inhibition dégénèrent (follicules pycnotiques et follicules en régression chez la femelle hypophysectomisée), la méiose tend à s'achever.

Dans le follicule mûr, on peut imaginer que la décharge gonadotrope ovulante a un double rôle : initialement, envoyer dans l'ovocyte un message qui sera responsable de la formation des fuseaux et des centrioles puis provoquer la dissociation physiologique entre les cellules de la granulosa et les cellules périovocytaires, cette dissociation physiologique étant rapidement suivie d'une dissociation mécanique, prélude à l'ovulation, dissociation qui à elle seule permet la reprise de la méiose.

Le schéma suivant est proposé comme une explication provisoire de l'ensemble des faits connus relatifs à la reprise de la méiose de l'ovocyte de Vache (fig. Ig).

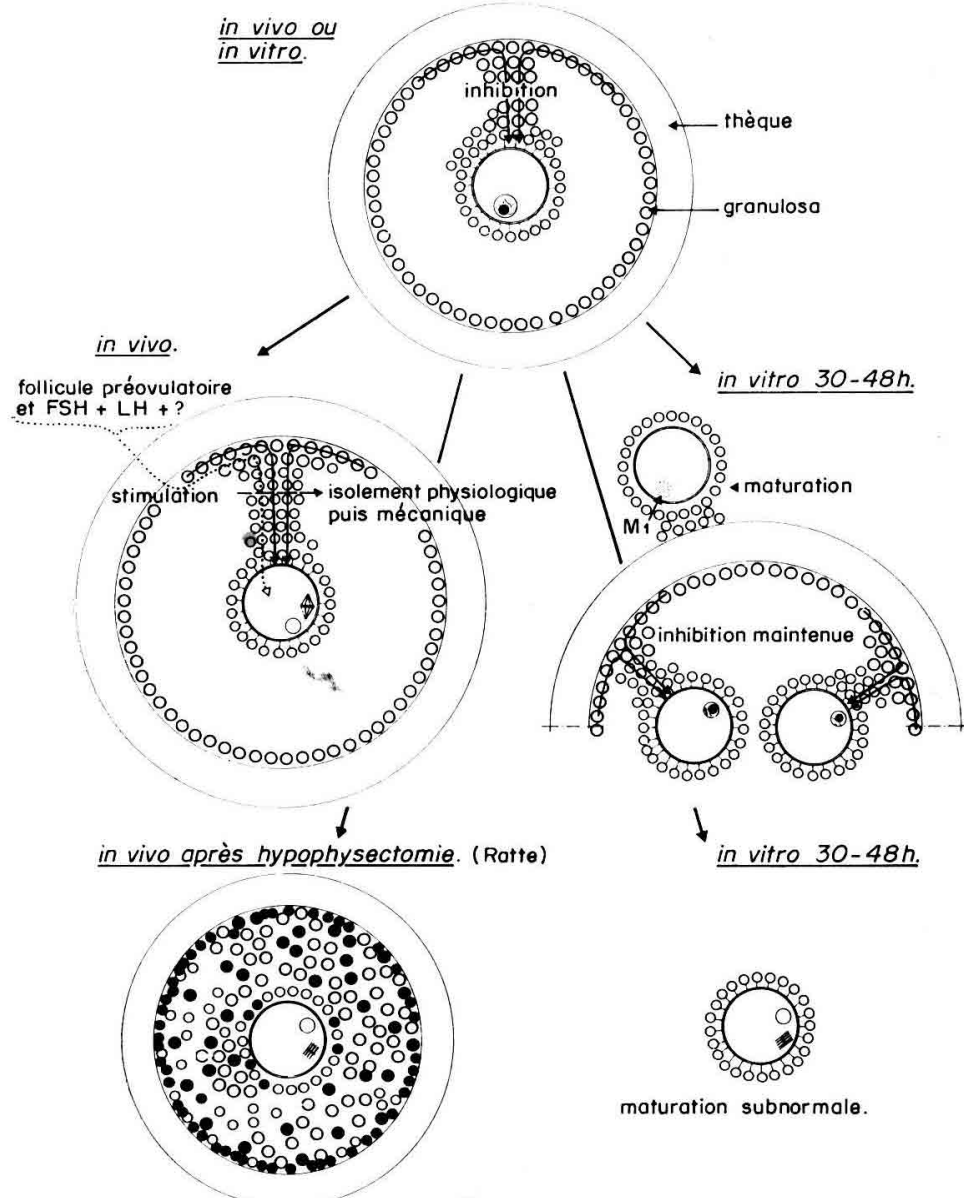

FIG. I9. - Représentation schématique des conditions du maintien du stade dictyé et de la maturation nucléaire de l'ovocyte de veau in vivo et in vitro

$3^{0}$ MoRICard (1940) a longuement développé l'hypothèse d'une fonction méiogène du liquide folliculaire. Telle quelle, à la lumière des faits rapportés, cette hypo- 
thèse paraît inexacte, puisqu'il apparaît que la reprise de la méiose correspond à la levée d'une inhibition et non à une stimulation. Cependant, nous voyons que la reprise de la méiose par explantation de l'ovocyte hors du follicule, présente des anomalies et qu'il est nécessaire de concevoir qu'au cours de la phase préovulatoire, une stimulation spécifique est transmise aux cellules périovocytaires, puis à l'ovocyte.

Les modifications structurales et ultrastructurales des cellules périovocytaires décrites par MORICARD et SALLUSTo (I968) sont peut-être le reflet du transfert de cet stimulation, mais peut-être révèlent-elles aussi le changement d'activité de ces cellules qui devenant indépendantes de la granulosa, doivent contribuer à assurer le métabolisme énergétique des ovocytes en maturation, comme l'ont montré BIGGERs, Whitmingham et Donahue (I967), Donahue et Stern (I968) et peut-être aussi leur propre utilisation de l'énergie du milieu.

Reçu pour publication en mars 1969.

\section{REMERCIEMENTS}

Ce travail a été réalisé grâce à l'aide de l'Institut national de la Recherche agronomique et de la Délégation générale à la Recherche scientifique (contrat numéro 63 FR 099).

Le séjour de l'un de nous a été rendu possible par l'aide de l'Université de Nevada et de l'U.S. Public Health Service et de l'I. N. R. A.

Nous remercions le Centre national de la Recherche scientifique et le docteur JuTrsz qui nous ont fourni les gonadotropines ovines utilisées.

\section{SUMMARY}

INVESTIGATIONS ON \& IN VITRO MATURATION OF COW AND PIG OOCYTES

Cow and Pig ovarian oocytes recovered from immature follicles were cultured in vitro. The resumption of meiosis was observed during culture, which is in accordance with previous literature by Pincus and Enzmann, Chang, Edwards, Suzuki and Mastrotanni (Pictures $Y$ and 2).

However, the position and structure of meiotic figures were often anomalous ; the formation of one or two " pronuclei " could even be noticed (Pictures $x$ to 6).

On the contrary, when the whole follicle was cultured in the same experimental medium, the follicular oocytes remained at the dictyate stage, provided that, in the Cow, the corona and granulosa cells remained alive (tables 3 and 4 ; pictures $7,8,11,13,14$ ).

The persistency of the dictyate stage in oocytes grafted on granulosa cells and on the other hand the resumption of meiosis in oocytes grafted on the theca constitute presumptive evidence that the granulosa cells are responsible for the inhibition of meiosis. (table 5 ; pictures 9, 10, I5, I6, 17, 18).

The grafting of a wedge of pituitary tissue on in vitro cultured, small-sized follicles, or the addition of steroids or ganodotrophins to the medium could not induce the nuclear maturation of follicular oocytes.

In view of these facts, it is suggested that in normal follicles, the preovulatory gonadotrophic release induces :

I) a specific stimulus triggering the normal nuclear maturation of the oocytes ;

2) a physiological or mechanical process responsible for the resumption of meiosis by isolating the oocyte from the granulosa cells. 


\section{RÉFÉRENCES BIBLIOGRAPHUQUES}

AUSTIN C. R., Barros C., 1968. Inhibition of ovulation by systematically administered actinomycin in the Hamster. Endocrinology, 83, $177-179$.

Biggers J. D., Whittingham D. G., Donahue R. P., 1967. The pattern of energy metabolism in the mouse oocyte and zygote. Proc. Nat. Acad. Sci., 48, 560-567.

Chang M. C., r955. The maturation of rabbit oocytes in culture and their maturation, activation, fertilizoation and subsequent development in the fallopian tubes. J. exp. Zool., 128, 378-406.

Donahue R. P., Stern S., ig68. Follicular cell support of oocyte maturation : production of pyruvate in vitro. J. Reprod. Fert., 17, 395-398.

EDWARDS R. G., I 965 a. Maturation in vilro of mouse, sheep, cow, pig, rhesus monkey and human ovarian oocytes. Nalure, 208, 349-351.

EDWARDS R. G., I965 b. Maturation in vitro of human ovarian oocytes. Lancet, 2, 926-929.

Edwards R. G., Banister B. D., Steptoe P. C., 1969. Early stages of fertilization in vitro of human oxytes matured in vitro. Nature, 281, 632-635.

Moricard R., I940. Méiose et gonadotropines. Facteurs hormonaux et cytoplasmiques de la division nucléaire. Bull. Biol., Suppl., 28.

Moricard R., Saluusto A., 1968. Cytophysiologie ultrastructurale de la méiose et de l'ovulation chez la Lapine. VI Congr. Internal. Reprod. Insém. Artif., Paris, juillet 1968, vol. I, I65-168.

Pincus G., EnZmann E. V., 1935. The comparative behavior of mammalian eggs in vivo and in vitro. $J$. Exp. Med., 62, 665-675.

Suzuki S., Mastroiann L., I966. Maturation of monkey ovarian follicular oocytes in vitro. Am. J.Obsl. Gynec., 86, 723-731.

\section{PLANCHE I}

Images de maturation d'ovocytes in vilro

I. Vache $I^{\text {re }}$ mitose réductionnelle, fuseau en tonnelet.

2. et 3 . Vache $I^{\text {er }} \mathrm{G}$. P. et $\mathbf{2}^{\mathbf{e}}$ fuseau de maturation anormal.

4. Truie $I^{r e}$ mitose, fuseau presque invisible.

5. Vache, pseudoparthénogenèse, deux pronuclei se sont formés sans aucun $G$. $P$.

6. Vache, pseudoparthénogenèse, une masse chromatique a été rejetée par l'ovocyte ; un pronucléus s'est formé. 

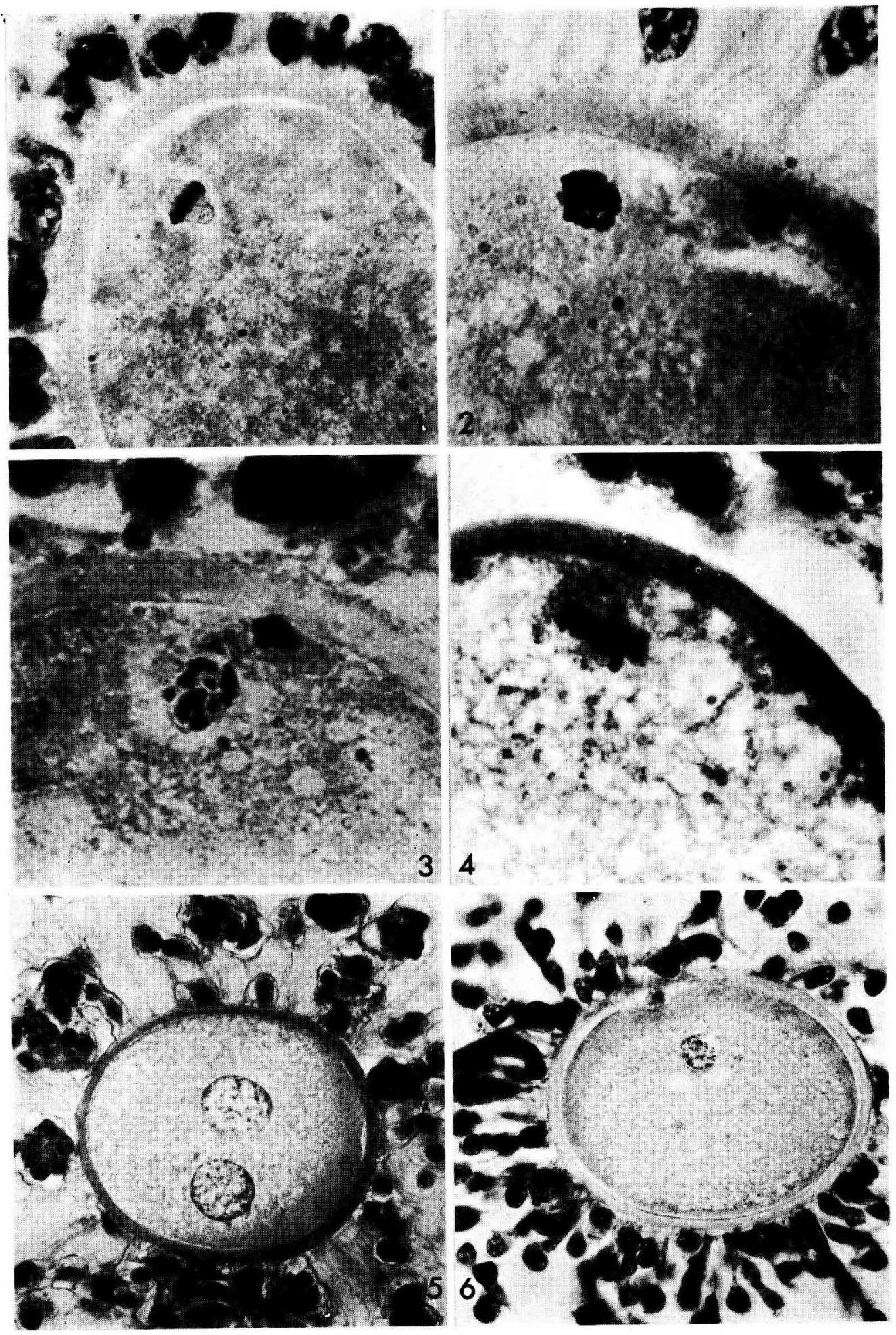


\section{PLANCHE II}

Ovocytes de Truie cultivés in vitro dans leur follicule

7. Follicule cultivé 48 heures, dont la granulosa est devenue pycnotique; ovocyte libre dans l'antrum; les chromosomes commencent seulement à apparaître.

8. Petit follicule réduit à sa basale et à la granulosa ; le noyau de 1'ovocyte est demeuré au stade dictyé ; culture de 48 heures.

Culture d'ovocytes de Truie in vitro sur des follicules

9. La « greffe » a lieu sur la thèque : l'ovocyte reprend sa méiose : plaque métaphasique bien visible (flèche). La coupe de l'ovocyte est subtangentielle et celui-ci paraît déformé.

Io. La greffe a lieu entre les coronas et la granulosa. On remarquera que chez la Truie les liaisons entre les cellules de la corona et 1'ovocyte sont très fragiles et que malgré une rupture évidente les ovocytes restent à l'état dictyé. 

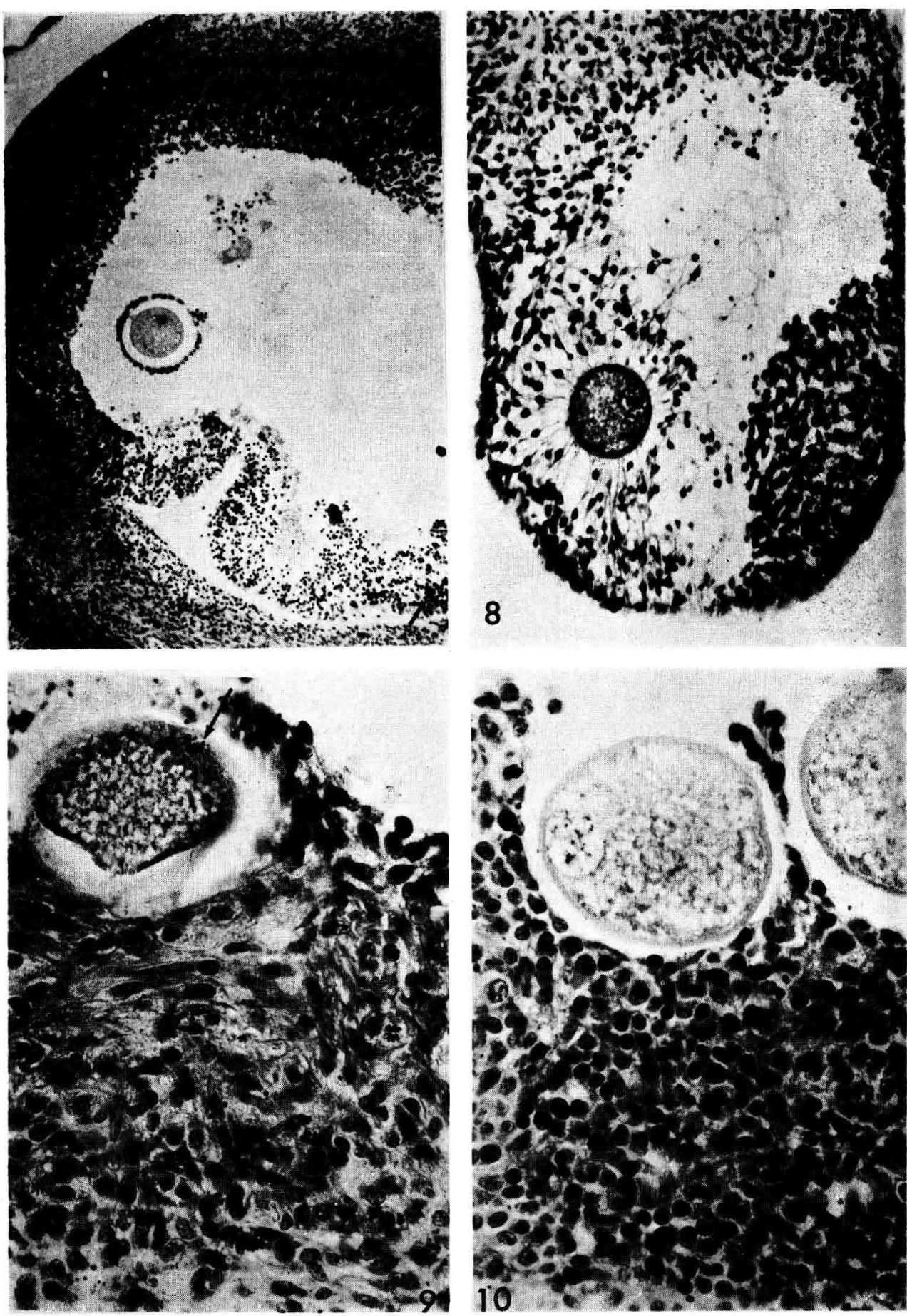

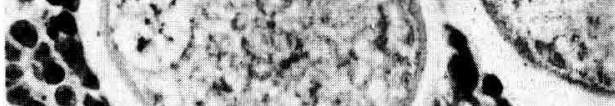

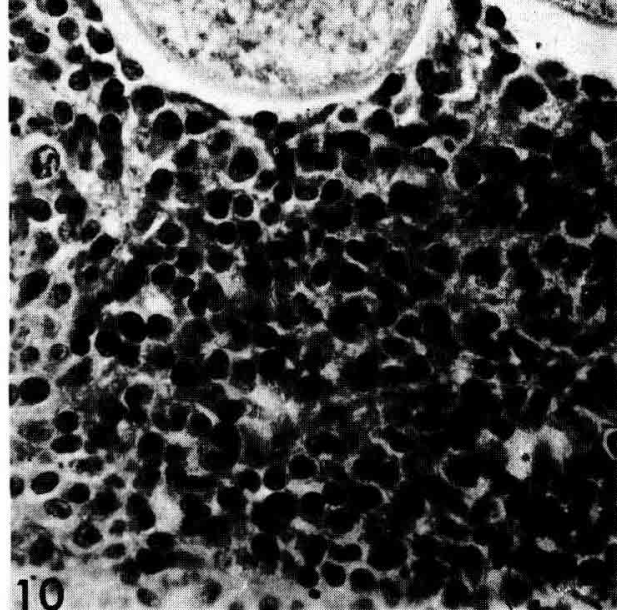


Ovocytes de Veau cultivés in vitro dans leur follicule

II. I follicule contenant 2 ovocytes. La corona de l'ovocyte du bas et la granulosa voisine sont intactes ; 1'ovocyte demeure au stade dictyé. La corona de l'ovocyte du haut et la granulosa voisine sont pycnotiques ; des chromosomes apparaissent.

I2. Ovocyte intrafolliculaire cultivé in vitro dans son follicule, en présence de deux fragments d'hypophyse qui se sont greffés sur le follicule ; après 48 heures le noyau est toujours à l'état dictyé.

I3. et I4. Détail des ovocytes de la figure II. 

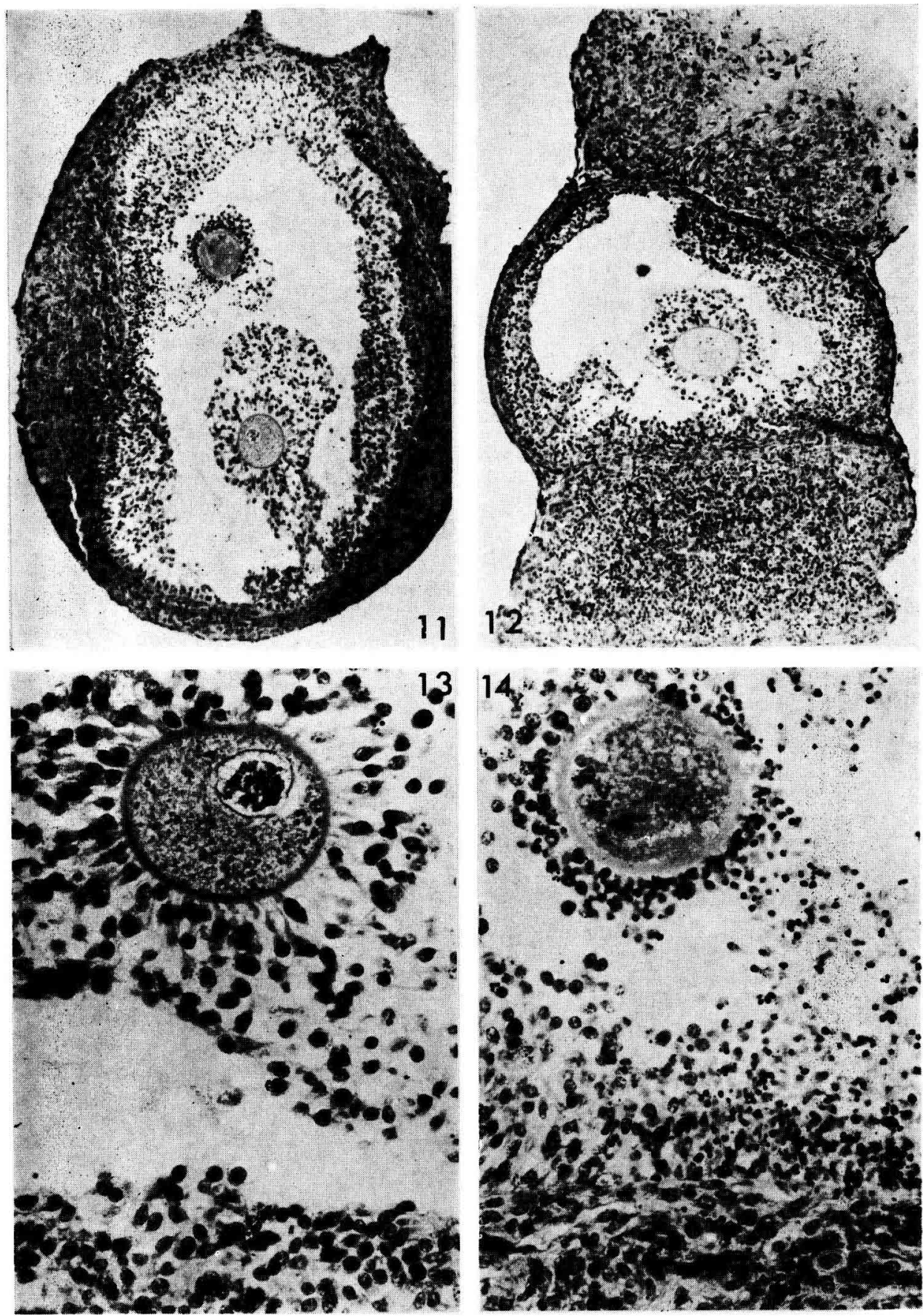

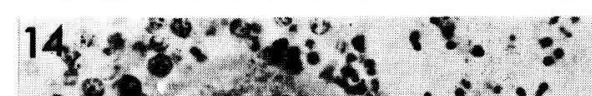

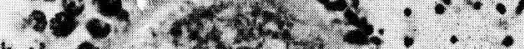

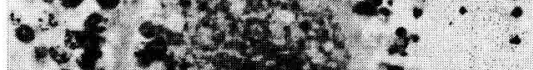
a

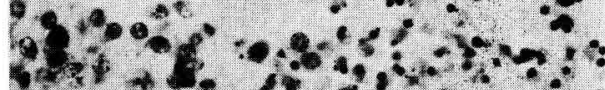

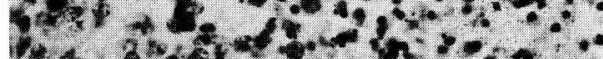

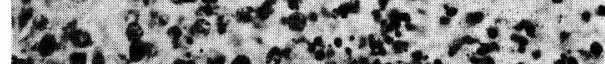

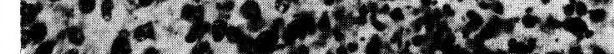

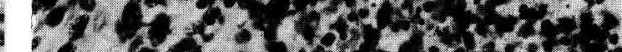

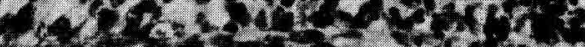

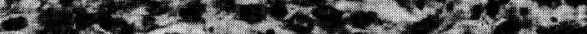

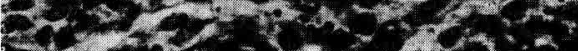

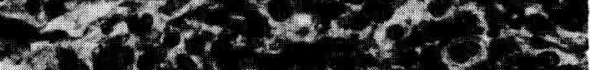

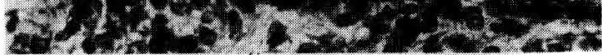




\section{PLANCHE IV}

Culture d'ovocytes de Vache in vitro sur des follictles

15. La corona s'est soudée à la granulosa, le noyau reste à l'état dictyé.

I6. La corona s'est soudée à la granulosa interne par le pont cellulaire qui figure entre les deux flèches : le noyau demeure dictyé.

I7. La corona s'est soudée à la granulosa, mais l'ensemble est devenu pycnotique; les deux ovocytes sont en métaphase I.

I8. La corona ovocytaire s'est dissociée et ne s'est pas soudée à la granulosa; la première métaphase est visible (flèche). 

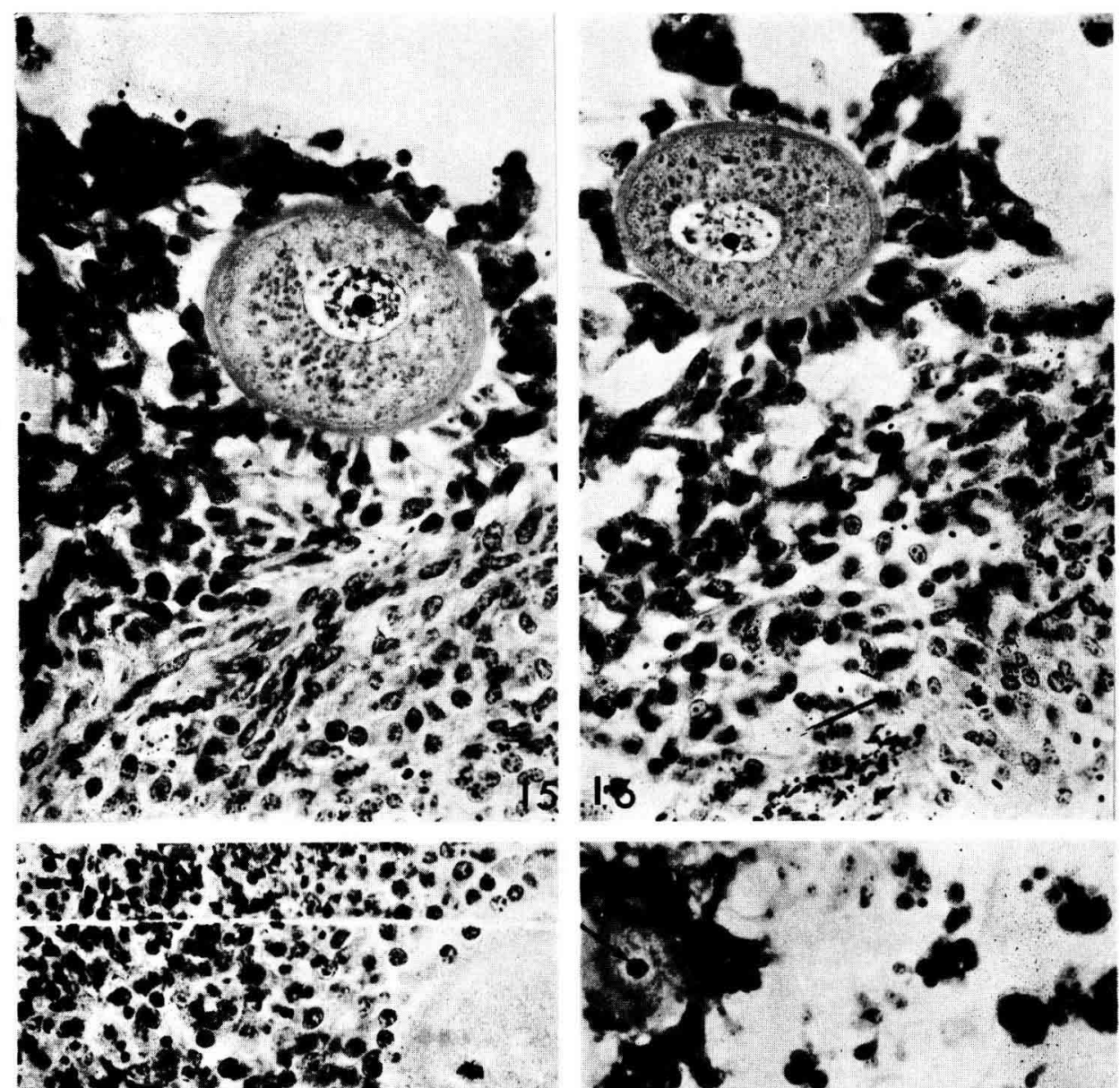
465. 034275. 3040.263

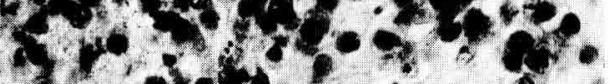
sonsery 2 - 20 . 2
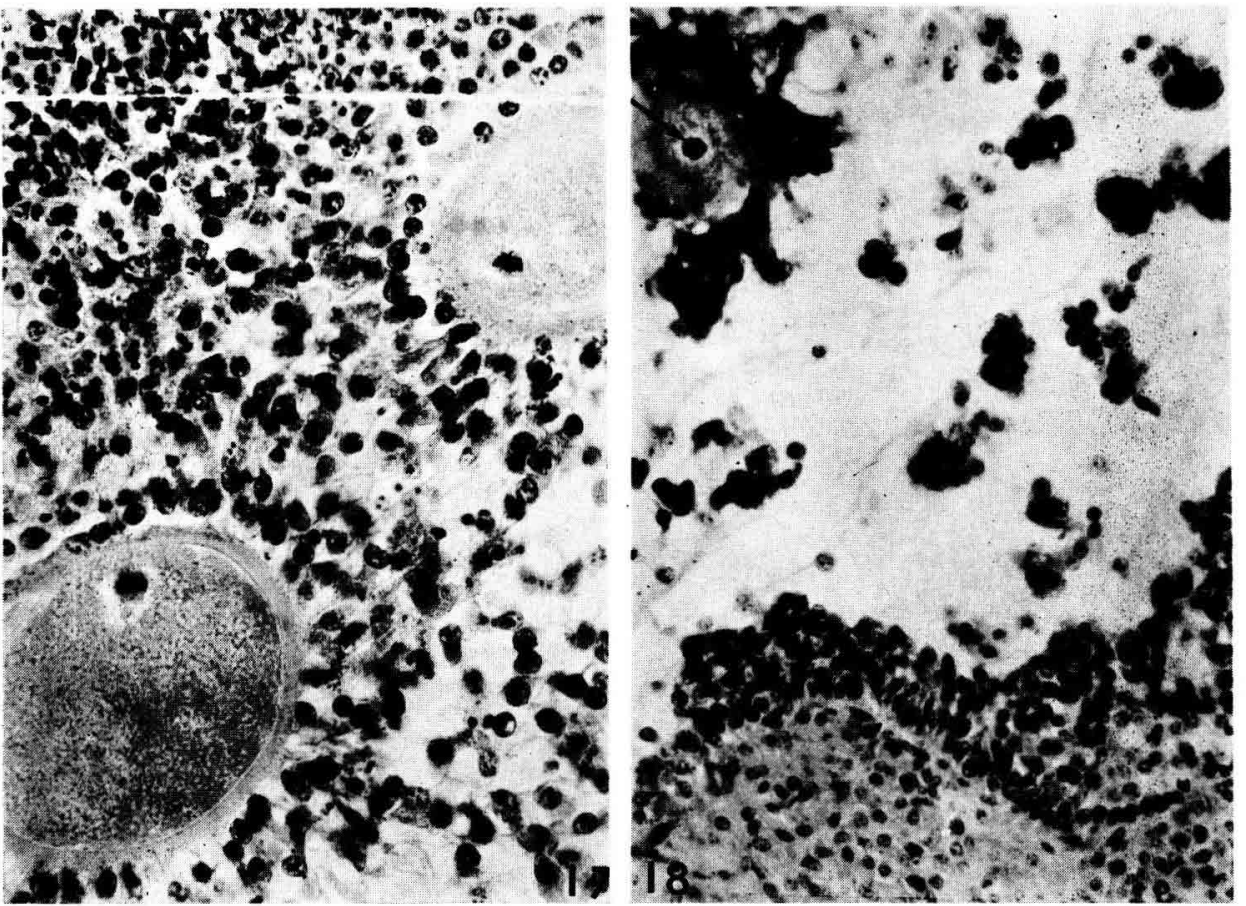